\title{
Control of Model Catalytic Conversion Reaction over Pt Nanoparticle Supported Mesoporous BEA Zeolite Catalysts
}

\author{
Junwoong Yoon ${ }^{\mathrm{a}}$ and Kyungsu $\mathrm{Na}^{\mathrm{b}, \mathrm{c}, *}$ \\ ${ }^{a}$ Department of Chemical Engineering, University of California, Berkeley, Berkeley, California \\ 94720, United States \\ ${ }^{b}$ Department of Chemistry, Chonnam National University, 77 Yongbong-ro, Buk-gu, Gwangju \\ 500-757, Korea \\ ${ }^{c}$ Department of Chemistry, University of California, Berkeley, Berkeley, California 94720, \\ United States
}

*Corresponding author. Tel: +82-62-530-3494, E-mail: kyungsu_na@chonnam.ac.kr

(C) 2015. This manuscript version is made available under the Elsevier user license http://www.elsevier.com/open-access/userlicense/1.0/ 


\begin{abstract}
Nanocrystalline mesoporous BEA zeolites supporting Pt metal nanoparticles have been investigated for the control of model catalytic reaction using methylcyclopentane as the reactant, while controlling the aluminum content in zeolite, Pt loading, Pt size and reaction temperature. Four different mesoporous BEA zeolites with different aluminum content were prepared via post-synthetic dealumination process with aqueous $\mathrm{HCl}$ solution. Pure mesoporous BEA zeolites without Pt metal nanoparticles converted methylcyclopentane to acyclic isomers via ringopening and dehydrogenated version of methylcyclopentane as the major products, whereas Pt metal nanoparticle supported counterparts produced $\mathrm{C}_{6}$-cyclic products (cyclohexane, benzene) most dominantly. In the case of Pt loading, the cyclohexane/benzene formation ratio decreased as the loading of Pt metal nanoparticle increased. As the Pt size increased from 2.5 to $5,7 \mathrm{~nm}$, cyclohexane selectivity decreased whereas benzene selectivity increased. However, their tendencies were not significant, which means that the size of Pt nanoparticle is not crucial for control of product selectivity. As the reaction temperature increased from 150 to $200,250^{\circ} \mathrm{C}$, cracking reaction pathway became much significant at the expense of that other reaction pathways were alleviated. This was due to the strong acidity of the mesoporous BEA zeolite support, which could be resolved by supporting Pt metal nanoparticles on weakly acidic mesoporous support such as aluminum-incorporated mesoporous silica.
\end{abstract}

\title{
Keywords
}

Pt nanoparticle, mesoporous zeolite, methylcyclopentane, activity, selectivity 


\section{Introduction}

Pt metal nanoparticle (NP) catalysts are widely used in current chemical industries as heterogeneous catalyst after supporting on porous materials having high surface area [1-3]. According to size and shape of Pt NPs, the catalytic reaction can be controlled, resulting in the enhancement of catalytic activity and change of product selectivity. In the catalytic process using Pt NPs, the reactant can be adsorbed onto the surface of Pt NPs with specific adsorption geometry and subsequently converted to various product molecules. The molecular interaction between the surface of Pt NPs and the reactant or even the shortlived intermediate species is the crucial factor for affecting the overall catalytic activity and the product selectivity [4-6]. In more practical catalytic reaction processes, the Pt NPs are used after supporting on the robust inorganic porous support materials that can bind the Pt NPs strongly on their surfaces, which allows this catalytic system to be used as recyclable heterogeneous catalysts. Accordingly, the physicochemical properties of supports can critically influence on the reaction processes in companion with Pt NPs [7-9].

In addition to the porous metal oxide materials, zeolites are also making huge contribution on the heterogeneous catalytic reactions. Indeed, zeolites are occupying more than $40 \%$ of solid catalysts in current chemical industries, which is the largest portion that is followed by metal oxides [10]. Zeolites are originally the microporous form of crystalline aluminosilicate structure, but in recent years, there have been many times introduced about new family of zeolite materials having mesoporous structure as well as the intrinsic micropores [11-15]. Such mesoporous zeolites, usually called as hierarchically nanoporous zeolites due to the co-existence of micropore and mesopore, opened new opportunities in catalysis due to the improved diffusion efficiency and the wide surface area with large pore volume [15]. Into the mesopores, various metal NPs with uniformly controlled size and shape can be supported, which consequently can be used as good model catalytic system. Recently, Pt metal nanoparticles supported on mesoporous BEA zeolites with different acidity were investigated for the control of product selectivity during methylcyclopentane conversion reaction [16-18]. This work is extending the previous work to 
study the role of mesoporous BEA zeolites without Pt NPs, effect of Pt loading and size, and effect of reaction temperature on the catalytic performance.

\section{Experimental}

\subsection{Catalyst preparation}

Four mesoporous BEA zeolites with different Al content were prepared via post-synthetic dealumination process of preformed mesoporous BEA zeolites synthesized with cyclic-diammonium type organic structure-directing agent (SDA) reported elsewhere [18]. For the synthesis of mesoporous BEA zeolite, sodium-silicate was used as the silica source and $\mathrm{Al}_{2}\left(\mathrm{SO}_{4}\right)_{3} 18 \mathrm{H}_{2} \mathrm{O}$ was used as the alumina source. The silica and the alumina sources were dissolved in water with $\mathrm{NaOH}$ and cyclic-diammonium SDA to give molar composition of $30 \mathrm{Na}_{2} \mathrm{O} / 5 \mathrm{Al}_{2} \mathrm{O}_{3} / 100 \mathrm{SiO}_{2} / 10 \mathrm{SDA} / 15 \mathrm{H}_{2} \mathrm{SO}_{4} / 6000 \mathrm{H}_{2} \mathrm{O}$. After aging for $1 \mathrm{~h}$ at room temperature, the mixture was transferred to a Teflon-coated stainless-steel autoclave and located in an oven equipped with tumbling system set at $170^{\circ} \mathrm{C}$. After $1 \mathrm{~d}$ treatment, the white precipitate was collected by filtration and washed with distilled water. Then, the sample was dried in an oven set at $120^{\circ} \mathrm{C}$, and subsequently calcined at $550^{\circ} \mathrm{C}$ in an air for $4 \mathrm{~h}$ to remove organic SDA. The calcined mesoporous BEA zeolite was further ion-exchanged to $\mathrm{H}^{+}$-form with $1 \mathrm{M} \mathrm{NH}_{4} \mathrm{NO}_{3}$ aqueous solution three separate times $\left(\mathrm{NH}_{4} \mathrm{NO}_{3} / \mathrm{Al}=10\right)$, and then, subsequently converted to the $\mathrm{H}^{+}$form through calcination in air at $550^{\circ} \mathrm{C}$ for $4 \mathrm{~h}$.

The $\mathrm{H}^{+}$-form mesoporous BEA zeolite was further treated with $1 \sim 2 \mathrm{M}$ of $\mathrm{HCl}$ solution to dealuminate from the zeolite framework post synthetically. In the post-treatment process, $0.5 \mathrm{~g}$ of $\mathrm{H}^{+}$-exchanged mesoporous BEA zeolite was diluted in $20 \mathrm{~mL}$ of $1 \sim 2 \mathrm{M} \mathrm{HCl}$ solutions, and heated for $30 \sim 90 \mathrm{~min}$ under reflux condition. After heat treatment, the zeolite was collected by filtration, washed with distilled water three times and dried in an oven at $120^{\circ} \mathrm{C}$. The resultant mesoporous BEA zeolite was denoted as BEA-x, where $\mathrm{x}$ is the content $(\%)$ of $\mathrm{Al}$ in the zeolite framework. 
For comparison, mesoporous silica MCF-17 was also prepared by following the literature published elsewhere [19]. In a synthesis process, 1,3,5-trimethylbenzene (TMB) was added to an aqueous solution of triblockcopolymer Pluoronic $\mathrm{P} 123$ and $\mathrm{HCl}$. After stirring of this solution for $2 \mathrm{~h}$ at $40^{\circ} \mathrm{C}$, tetraethylorthosilicate (TEOS) as the silica source was added and the solution was stirred for an additional $20 \mathrm{~h}$. Subsequently, $\mathrm{NH}_{4} \mathrm{~F}$ was then added, and the solution was hydrothermally heated at $100^{\circ} \mathrm{C}$ for $24 \mathrm{~h}$. After then, the white precipitate was collected by filtration, dried, and then calcined for $6 \mathrm{~h}$ at $550^{\circ} \mathrm{C}$. The resultant pure silica $\mathrm{MCF}-17$ was further treated with $\mathrm{AlCl}_{3}$ diluted in ethanol solution to incorporate $\mathrm{Al}$ atoms on the surface of mesopore wall [20-21]. More specifically, the calcined MCF-17 was slurred with anhydrous $\mathrm{AlCl}_{3}$ in absolute ethanol, in order to give $\mathrm{Al}$ content of $10 \%$. The slurring solution was stirred overnight at room temperature, and then the ethanol was removed by rotary-evaporation. The precipitated Al-grafted MCF-17 ( $\left.\mathrm{Al}-\mathrm{SiO}_{2}\right)$ was dried at $130^{\circ} \mathrm{C}$ for $1 \mathrm{~h}$, and subsequently calcined at $550^{\circ} \mathrm{C}$ for $4 \mathrm{~h}$ in air. The calcined $\mathrm{Al}-\mathrm{SiO}_{2}$ sample was slurred in $1 \mathrm{M}$ of $\mathrm{NH}_{4} \mathrm{NO}_{3}$ aqueous solution for $4 \mathrm{~h}$ at room temperature to introduce acidic sites and the next process is same to the process described above.

Poly(vinylpyrrolidone) (PVP)-capped Pt nanoparticles (NPs) with an average size of 2.5, 5 and $7 \mathrm{~nm}$ were synthesized by following the literature reported elsewhere $[6,22]$. In a typical synthesis of $2.5 \mathrm{~nm}$ Pt NPs, $\mathrm{H}_{2} \mathrm{PtCl}_{6}$ was used as Pt precursor, which was dissolved in ethylene glycol in the presence of PVP $(\mathrm{MW}=55,000)$. This solution was reacted at $180^{\circ} \mathrm{C}$, and the as-synthesized PVP-capped Pt NPs were collected by centrifugation, washed and re-dispersed in ethanol to give colloidal solution of Pt NPs with the concentration of ca. $1 \mathrm{mg} / \mathrm{mL}$. This colloidal solution of Pt NPs was added to the supporting materials (zeolites) and the colloidal suspension was sonicated for $5 \mathrm{~h}$ at room temperature using a commercial ultrasonic cleaner (Branson, 1510R-MT, 70W, $42 \mathrm{kHz}$ ) to give desired loading of Pt (ca. $0.1 \sim 0.5 \mathrm{wt} \%$ ). The brown precipitates were separated by centrifugation $(10,000 \mathrm{rpm}, 5 \mathrm{~min})$, washed with ethanol for four times, and dried in an oven at $60^{\circ} \mathrm{C}$ overnight.

\subsection{Characterization}


X-ray diffraction (XRD) patterns were taken with a Bruker D8 Venture diffractometer equipped with $\mathrm{Cu}$ tube operated at $40 \mathrm{~W}(40 \mathrm{kV}, 1 \mathrm{~mA})$. Transmission electron microscope (TEM) images were taken with a Hitachi H-7650 TEM operated at $120 \mathrm{kV}$. Elemental analyses by inductively coupled plasma atomic emission spectroscopy (ICP-AES) was performed using a PerkinElmer optical emission spectrometer (Optima $7000 \mathrm{DV}) . \mathrm{N}_{2}$ physisorption analysis for determination of surface area and mesopore size was carried out using Micromeritics ASAP2020 volumetric analyzer at the liquid nitrogen temperature $(77 \mathrm{~K})$. The surface area was calculated by Brunauer-Emmett-Teller (BET) equation from the adsorption data obtained at $\mathrm{P} / \mathrm{P}_{0}$ values between 0.05 and 0.2 . The average mesopore size was determined from the adsorption branch of the isotherm using the Barrett-Joyner-Halenda (BJH) algorithm.

\subsection{Catalytic reaction}

The catalytic testing was performed using lab-built plug-flow reactor connected to a Hewlett Packard 5890 gas chromatograph (GC). A $10 \%$ SP-2100 on 100/120 Supelco port packed column in line with a FID detector was used to separate and analyze the $C_{1}-C_{6}$ hydrocarbons. Mass flow controllers were carefully calibrated using a bubble flow meter and used to introduce the ultra-high purity (99.9999 \% Praxair) $\mathrm{H}_{2}$ and $\mathrm{He}$ gases. Saturated vapor pressure of methylcyclopentane (MCP) was introduced to the reactor using a bubbler at room temperature $\left(22^{\circ} \mathrm{C}\right)$. The reactant flow was carefully calibrated at different temperatures and partial pressures of He carrier. A total flow of $40 \mathrm{ml} / \mathrm{min}$ was used. Partial pressure of reactants was calculated by using the known temperature vs. saturated vapor pressure plots and was 10 Torr with 50 Torr of $\mathrm{H}_{2} .50$ - $100 \mathrm{mg}$ charges of the catalysts were diluted by quartz sand with average granular size of $0.4 \mathrm{~mm}$ and loaded in the reactor bed. The actual weight of catalyst used was adjusted to give similar total conversions in each case. Prior to catalytic testing, the catalysts were treated at $250^{\circ} \mathrm{C}$ for 1 hour under a flow of first $\sim 200$ Torr $\mathrm{O}_{2}$ and $\sim 560$ Torr He (i.e. oxidization step); and then $\sim 200$ Torr $\mathrm{H}_{2}$ and $\sim 560$ Torr $\mathrm{He}$ (i.e. reduction step). The reaction was performed at the temperature of 150, 200 and 
$250^{\circ} \mathrm{C}$ at $1 \mathrm{~atm}$ with WHSV of $240 \mathrm{~h}^{-1}$ and the residence time of $\sim 0.9 \mathrm{~s}$. The catalytic activity and selectivity were evaluated for total (MCP) conversions around 5\%.

\section{Results and Discussion}

Figure 1A shows XRD patterns for the series of mesoporous BEA zeolites, which proved that the initial crystallinity of pristine mesoporous BEA zeolite was fully maintained upon post-dealumination. Inductively coupled plasma-atomic emission spectroscopy (ICP-AES) characterized that the four zeolites have $\mathrm{Al}$ content of $10,4,1$ and $0.5 \%$, respectively. $\mathrm{N}_{2}$ adsorption analysis proved that the postdealumination on the mesoporous BEA zeolites was not detrimental for maintaining the initial porous structure of pristine mesoporous BEA zeolite (Fig. 1B). The average mesopore diameter was around 15 $\mathrm{nm}$ (Fig. 1B inset) and the BET surface areas were $750 \sim 900 \mathrm{~m}^{2} \mathrm{~g}^{-1}$ over the series of mesoporous zeolites (Table 1). Figure 2 shows the transmission electron micrographs (TEM) of four mesoporous BEA zeolites supporting $2.5 \mathrm{~nm}$ Pt NPs, which clearly shows that the Pt NPs with uniform size are dispersed well in the mesopore voids. The overall morphologies of four zeolites are aggregated particle with BEA zeolite nanocrystals, which are not different significantly each other.

The series of mesoporous BEA zeolites with and without supporting Pt metal NPs was tested for the MCP conversion reaction. Scheme 1 the reaction pathway wherein MCP can be converted into various hydrocarbon species such as dehydrogenated MCP through dehydrogenation (1, green), acyclic isomers through ring-opening followed with isomerization (2, pink), cyclohexane through ring-enlargement followed with hydrogenation of cyclohexene (3, blue), benzene through ring-enlargement followed with dehydrogenation of cyclohexene $(4$, red $)$ and $\mathrm{C}_{1}-\mathrm{C}_{5}$ hydrocarbons through cracking process $(5$, gray). For the formation of cyclohexane and benzene, MCP can go through cyclohexene as the intermediate species as proved by in situ sum-frequency generation spectroscopy previously [16]. As the reference data, pure mesoporous BEA zeolites without Pt NPs are investigated in this reaction. The result in Figure 3A shows the product yield calculated in a given reaction time and catalyst mass over four mesoporous BEA zeolites (BEA-10, 4, 1, and 0.5 ) obtained at $150^{\circ} \mathrm{C}$. This result indicate that the pure zeolites with only 
acidic catalytic function can lead the dehydrogenation (green) and ring-opening followed with isomerization (pink) reactions. The total yield over BEA-10 is $0.37 \mathrm{mmol} / \mathrm{h} / \mathrm{g}$ that was reduced down to $0.12 \mathrm{mmol} / \mathrm{h} / \mathrm{g}$ for BEA-0.5. As the $\mathrm{Al}$ content decreased total product yield decreased, but the yield of ring-opening followed with isomerization (pink) decreased much more significantly than the yield of dehydrogenation. As reported previously [17], the BEA-0.5 zeolite has relatively more Brönsted acid sites than Lewis acid sites, which might trigger the dehydrogenation reaction pathway than the ring-opening with isomerization pathway.

In the mesopore voids of four BEA zeolites, $2.5 \mathrm{~nm}$ PVP-capped Pt metal NPs were supported to give similar Pt loading at ca. $0.2 \mathrm{wt} \%$. All the Pt supported four BEA zeolites produced $\mathrm{C}_{6}$-cyclic hydrocarbons (benzene and cyclohexane) as the major products with $80 \sim 90 \%$ selectivity. Figure 3B graphitized the product yield for benzene (red) and cyclohexane (blue) excluding other minor products. All four catalyst systems showed product yield at $1.5 \sim 2.0 \mathrm{mmol} / \mathrm{h} / \mathrm{g}$, which is $5 \sim 10$ times higher yield than those of pure BEA zeolites without Pt NPs. Among the series of Pt supported mesoporous BEA zeolite, Pt/BEA-10 produced the largest yield of cyclohexane $(1.27 \mathrm{mmol} / \mathrm{h} / \mathrm{g})$ whereas $\mathrm{Pt} / \mathrm{BEA}-0.5$ produced the largest yield of benzene $(0.96 \mathrm{mmol} / \mathrm{h} / \mathrm{g})$. This means that the Pt/BEA-0.5 highly likely dehydrogenate the cyclohexene intermediate species whereas the Pt/BEA-10 do the hydrogenation of cyclohexene more to make cyclohexane. This tendency is consistent with the behaviors of pure BEA zeolites without Pt NPs. As indicated above, the BEA-0.5 zeolite triggers the dehydrogenation more preferentially than the ring-opening followed with isomerization wherein hydrogenation step was involved to make the acyclic isomers.

Effect of Pt loading was also investigated in given zeolites BEA-10 and BEA-0.5. The loading of Pt was varied with $0.1,0.2$ and $0.4 \mathrm{wt} \%$, which resultantly allows to study the effect of Pt/acid site ratio. The results are shown in Figure 4. As the Pt loading increased in the catalyst, total product yield increased systematically, which is common in both Pt/BEA-10 and Pt/BEA-0.5 catalyst systems. In Pt/BEA-10 system, as the Pt loading increased, benzene yield increased much more significantly than cyclohexane (Figure 4A). Benzene yield increased from 0.29 to 0.71 and up to 1.75 , whereas cyclohexane yield 
increased from 0.78 to 1.27 and up to 2.21. In the case of Pt/BEA-0.5 system, as the Pt loading increased, benzene yield also increased significantly but no significant increase in cyclohexane yield was observed (Figure 4B). These results indicate that the Pt/acid site ratio plays an important role for control of absolute product yield and relative product selectivity between benzene and cyclohexane. In addition, if the metal $\mathrm{NP} /$ zeolite catalyst system can be controlled carefully, the $100 \%$ product selectivity with the highest yield can be achieved in an ideal point of view.

Size of metal NPs often plays a critical factor for changing the product selectivity in a given catalytic process [4-6]. In the present work, effect of Pt size was also investigated by making not only $2.5 \mathrm{~nm}$, but also 5 and $7 \mathrm{~nm}$ in average size. Three different sized Pt NPs were supported on BEA-10 and BEA-0.5 zeolites, and tested in the same reaction condition. Figure 5 shows the $\%$ selectivity of Pt/BEA-10 and Pt/BEA-0.5 catalysts with 2.5, 5 and $7 \mathrm{~nm}$ Pt NPs. As the size of Pt NPs increased, benzene selectivity decreased at the expense of increase in cyclohexane selectivity for both Pt/BEA-10 (Figure 5A) and Pt/BEA-0.5 (Figure 5B) catalyst systems. However, the increase and decrease tendencies for benzene and cyclohexane, respectively, are not so significant as compared to the effect of Pt loading.

The catalytic reaction using Pt/BEA-10 was also performed at above $150^{\circ} \mathrm{C}$ to investigate the effect of reaction temperature on the change in product selectivity. Figure $6 \mathrm{~A}$ shows the change of product selectivity over Pt/BEA-10 catalyst (Pt loading = ca. $0.2 \mathrm{wt} \%$ ) according to the change in reaction temperature from 150 to 200 and $250^{\circ} \mathrm{C}$. As the reaction temperature increases, significant increase is observed for the cracking product (grey). This cracking was not observed at $150^{\circ} \mathrm{C}$, but the cracking selectivity reached to 30 and $65 \%$ at 200 and $250^{\circ} \mathrm{C}$, respectively. The formation of other products was inhibited significantly. This is because the strong acid sites on the zeolite surface governs the catalytic reaction more strongly than the Pt NPs as the reaction temperature increases. However, such dominant formation of cracking products was made to almost zero, by using the less acidic catalytic support instead of the mesoporous BEA zeolite (Figure 6B). The mesoporous silica MCF-17 was post-treated with $\mathrm{AlCl}_{3}$ in ethanol to incorporate $\mathrm{Al}$ atoms on the surface of mesopore wall $\left(\mathrm{Al}-\mathrm{SiO}_{2}\right)$, which introduced the weakly acidic sites on the mesoporous framework with ca. $10 \%$ aluminum [23]. The $\mathrm{Al}-\mathrm{SiO}_{2}$ sample 
showed typical mesoporous structure with $24 \mathrm{~nm}$ in average mesopore diameter (Table 1), which showed negligible catalytic activity on MCP conversion. However, when $2.5 \mathrm{~nm}$ Pt NPs were supported on the mesoporous channel the $\mathrm{Pt} / \mathrm{Al}-\mathrm{SiO}_{2}-10$ catalyst produced benzene with about $35 \%$ selectivity at $150^{\circ} \mathrm{C}$. However, the benzene selectivity increased up to $\sim 80 \%$ upon increase of reaction temperature to 200 and $250^{\circ} \mathrm{C}$. Although the activity of $\mathrm{Pt} / \mathrm{Al}-\mathrm{SiO}_{2}-10$ at $150^{\circ} \mathrm{C}$ is about $1 / 3$ of $\mathrm{Pt} / \mathrm{BEA}-10$ catalyst, $\mathrm{Pt} / \mathrm{Al}-\mathrm{SiO}_{2}-10$ catalyst is more promising to make almost negligible amount of cracking products at higher reaction temperature.

\section{Conclusions}

In conclusion, mesoporous BEA zeolites supporting Pt metal nanoparticles have been investigated as the heterogeneous catalysts in the conversion of methylcyclopentane. The supported catalyst system produced $\mathrm{C}_{6}$-cyclic hydrocarbons (benzene and cyclohexane) with high selectivity ( 90\%), where the benzene and cyclohexane product yields can be controlled by Pt loading and Al content in the zeolites significantly, and by $\mathrm{Pt}$ size relatively less significantly. More specifically, it is demonstrated that the cyclohexane/benzene formation ratio decreased as the loading of Pt metal nanoparticle increased. In addition, change of Pt size from 2.5 to $5,7 \mathrm{~nm}$ decreased cyclohexane selectivity and increased benzene selectivity. Although the Pt metal nanoparticles supported on mesoporous BEA zeolite catalysts achieved high product selectivity to $\mathrm{C}_{6}$-cyclic hydrocarbons with high yields for benzene (up to $0.96 \mathrm{mmol} / \mathrm{h} / \mathrm{g}$ ) and cyclohexane (up to $1.27 \mathrm{mmol} / \mathrm{h} / \mathrm{g}$ ) at $150^{\circ} \mathrm{C}$ with $2 \mathrm{wt} \%$ Pt loading, their high selectivity was significantly decreased due to the strong acidity of zeolite framework that can trigger the cracking reaction pathway upon increase of reaction temperature up to $200 \sim 250^{\circ} \mathrm{C}$. This could be resolved by supporting Pt metal nanoparticles on weakly acidic mesoporous support such as aluminum-incorporated mesoporous silica. 


\section{Acknowledgements}

This work was supported by the Korea CCS R\&D Center (KCRC) grant funded by the Korea government (Ministry of Science, ICT \& Future Planning) (no. NRF-2014M1A8A1049254).

\section{References}

[1] R. M. Rioux, H. Song, J. D. Hoefelmeyer, P. Yang, G. A. Somorjai, J. Phys. Chem. B 109 (2005) 2192-2202.

[2] S. Alayoglu, A. U. Nilekar, M. Mavrikakis, B. Eichhorn, Nature Mater. 7 (2008) 333-338.

[3] S. Alayoglu, V. V. Pushkarev, N. Musselwhite, K. An, S. Beaumont G. A. Somorjai. Top. Catal. 55 (2012) 723-730.

[4] G. A. Somorjai, J. Y. Park, Top. Catal. 49 (2008) 126-135.

[5] C.-K. Tsung, J. N. Kuhn, W. Huang, C. Aliaga, L. Hung, G. A. Somorjai, P. Yang, J. Am. Chem. Soc. 131 (2009) 5816-5822.

[6] V. V. Pushkarev, N. Musselwhite, K. An, S. Alayoglu, G. A. Somorjai, Nano Lett. 12 (2012) 5196-5201.

[7] S. Alayoglu, C. Aliaga, C. Sprung, G. A. Somorjai, Catal. Lett. 141 (2011) 914-924.

[8] H. Li, Z. Bian, J. Zhu, D. Zhang, G. Li, Y. Huo, H. Li, Y. Lu, J. Am. Chem. Soc. 129 (2007) 8406-8407.

[9] A. B. Boffa, C. Lin, A. T. Bell, G. A. Somorjai, Catal. Lett. 27 (1994) 243-249.

[10] R. Rinaldi, F. Schüth, Energy Environ. Sci. 2 (2009) 610-626.

[11] K. Na, M. Choi, R. Ryoo, Micropor. Mesopor. Mater. 166 (2013) 3-19.

[12] M. Choi, K. Na, J. Kim, Y. Sakamoto, O. Terasaki, R. Ryoo, Nature 461 (2009) 246-249.

[13] K. Na, C. Jo, J. Kim, K. Cho, J. Jung, Y. Seo, R. J. Messinger, B. F. Chmelka, R. Ryoo, Science 333 (2011) 328-332.

[14] K. Na, M. Choi, W. Park, Y. Sakamoto, O. Terasaki, R. Ryoo, J. Am. Chem. Soc. 132 (2010) 41694177. 
[15] J. Kim, M. Choi, R. Ryoo, J. Catal. 269 (2010) 219-228.

[16] K. Na, N. Musselwhite, X. Cai, S. Alayoglu, G. A. Somorjai, J. Phys. Chem. A 118 (2014) 8446-845 2.

[17] K. Na, S. Alayoglu, R. Ye, G. A. Somorjai, J. Am. Chem. Soc. 136 (2014) 17207-17212.

[18] K. Na, M. Choi, R. Ryoo, J. Mater. Chem. 19 (2009) 6713-6719.

[19] S. Alayoglu, C. Aliaga, C. Sprung, G. A. Somorjai. Cat. Lett. 141 (2011) 914-924.

[20] S. Jun, R. Ryoo, J. Catal. 195 (2000) 237-243.

[21] N. Musselwhite, K. Na, S. Alayoglu, G. A. Somorjai, J. Am. Chem. Soc. 136 (2014) 16661-16665.

[22] K. An, S. Alayoglu, N. Musselwhite, S. Plamthottam, G. Melaet, A. E. Lindeman, G. A. Somorjai, J. Am. Chem. Soc. 135 (2013) 16689-16696.I

[23] N. Musselwhite, K. Na, K. Sabyrov, S. Alayoglu, G. A. Somorjai, J. Am. Chem. Soc. 137 (2015) 10231-10237. 


\section{Figures and Tables}

Table 1. Physicochemical properties of support materials tested in this work.

\begin{tabular}{|c|c|c|c|c|}
\hline Sample & Al content $(\%)$ & $\begin{array}{c}\text { BET surface area } \\
\left(\mathrm{m}^{2} / \mathrm{g}\right)\end{array}$ & $\begin{array}{c}\text { Total pore volume } \\
\left(\mathrm{cm}^{3} / \mathrm{g}\right)\end{array}$ & $\begin{array}{c}\text { Average mesopore diameter } \\
(\mathrm{nm})\end{array}$ \\
\hline BEA-10 & 10 & 755 & 0.85 & 20 \\
\hline BEA-4 & 4 & 815 & 0.93 & 18 \\
\hline BEA-1 & 1 & 770 & 0.86 & 11 \\
\hline BEA-0.5 & 0.5 & 865 & 1.23 & 24 \\
\hline $\mathrm{Al}_{-} \mathrm{SiO}_{2}$ & 10 & 720 & 1.89 & 13 \\
\hline
\end{tabular}
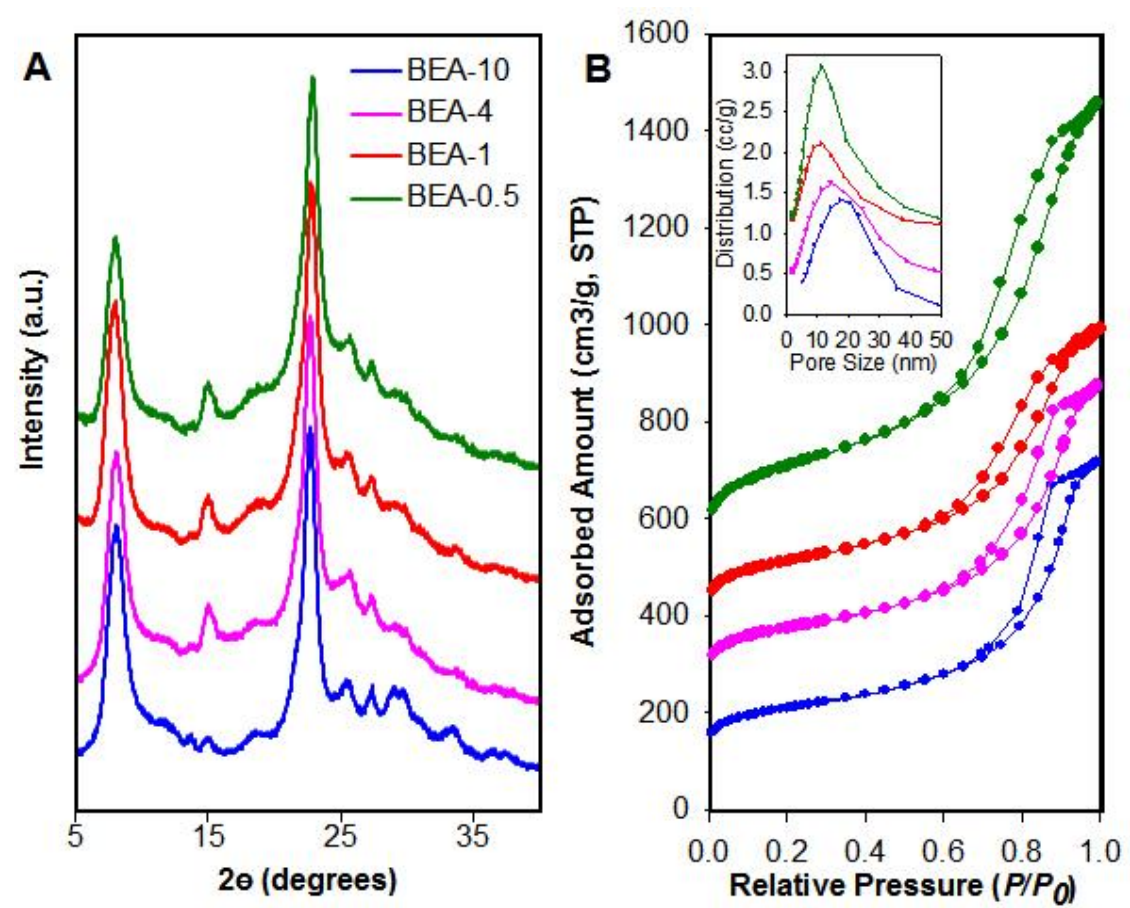

Figure 1. X-ray diffraction patterns (A), $\mathrm{N}_{2}$ adsorption isotherms (B) and pore size distributions (B, inset) of BEA-10, BEA-4, BEA-1 and BEA-0.5 zeolites. 

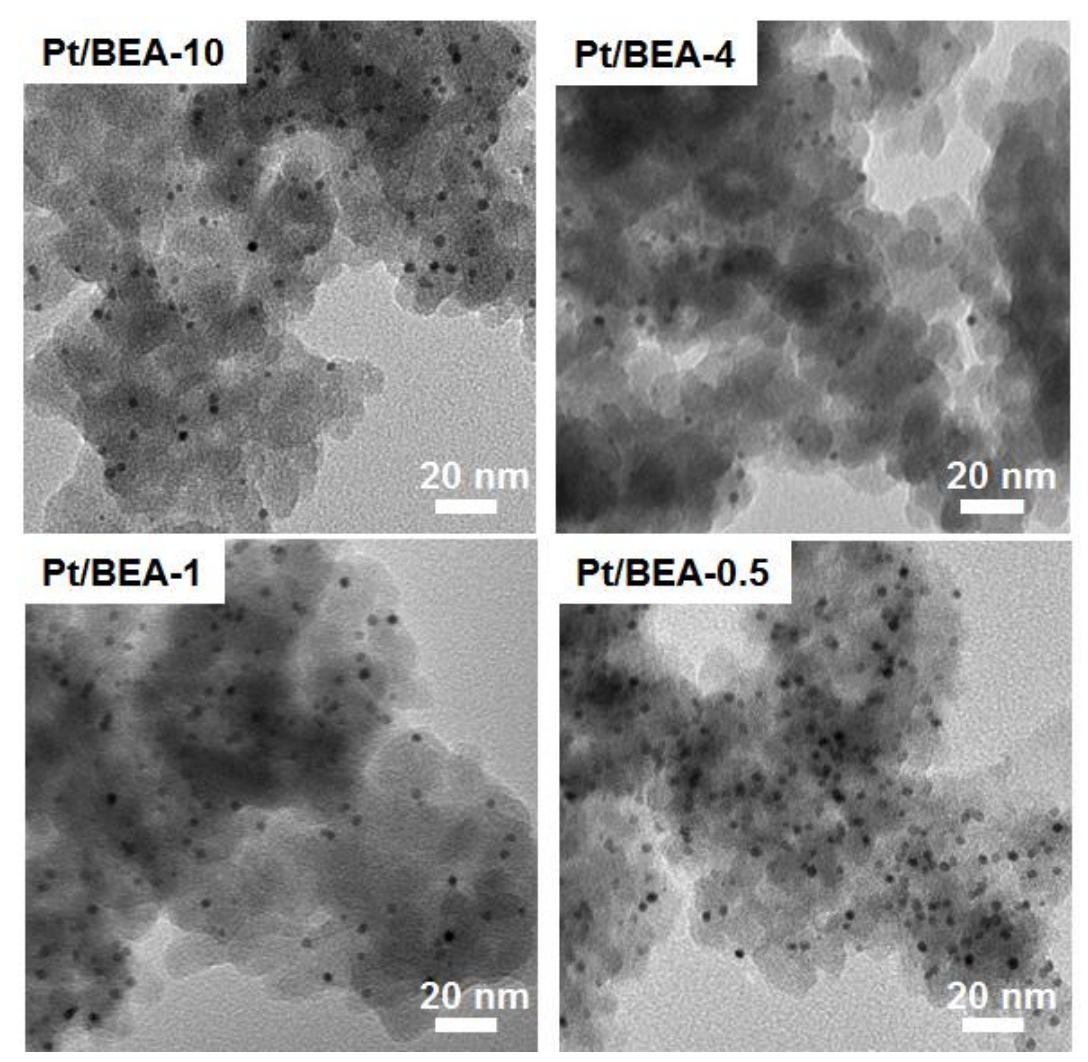

Figure 2. Transmission electron micrograph images of Pt/BEA-10, Pt/BEA-4, Pt/BEA-1 and Pt/BEA-0.5 catalysts where $2.5 \mathrm{~nm}$ sized Pt metal nanoparticles were supported.

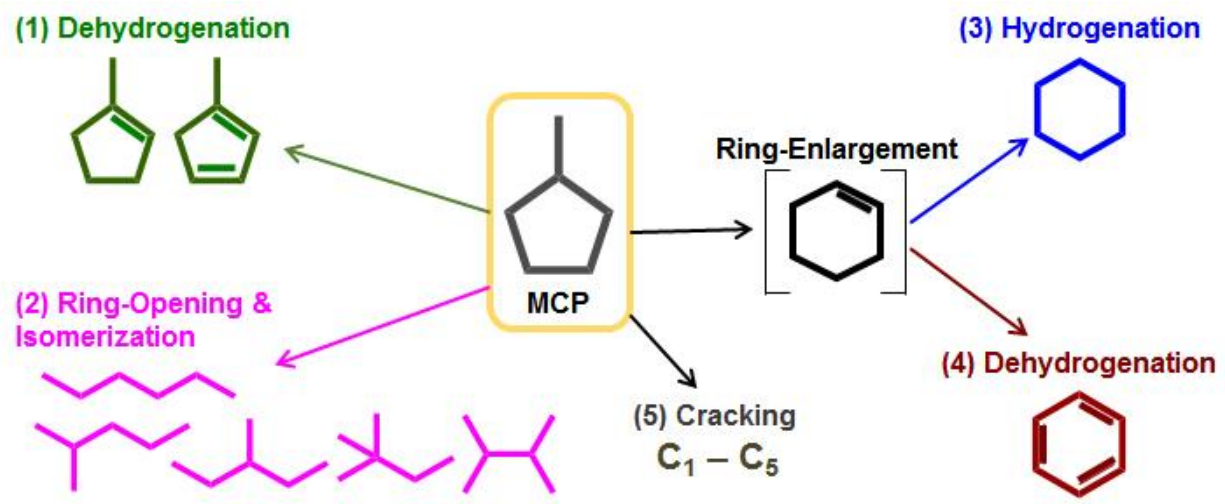

Scheme 1. Schematic drawing for the reaction of methylcyclopentane (MCP) conversion. MCP can be dehydrogenated (green), ring-opened followed with isomerized (pink), ring-enlarged to cyclohexane (blue) and benzene (red), and cracked to $\mathrm{C}_{1}-\mathrm{C}_{5}$ hydrocarbons . 

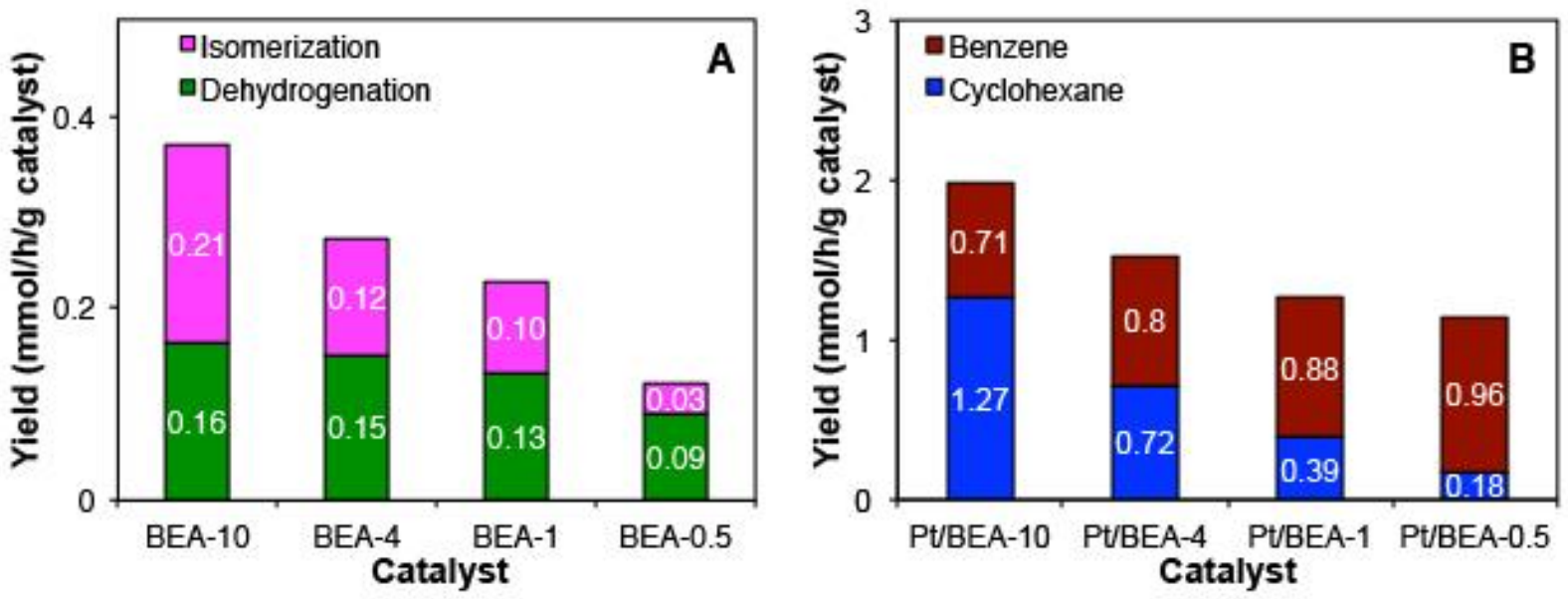

Figure 3. (A) Product yield to ring-opened isomers (pink) and dehydrogenated MCP (green) over four BEA zeolites without Pt, and (B) product yield to benzene (red) and cyclohexane (blue) over four Pt/BEA zeolites with different aluminum contents.
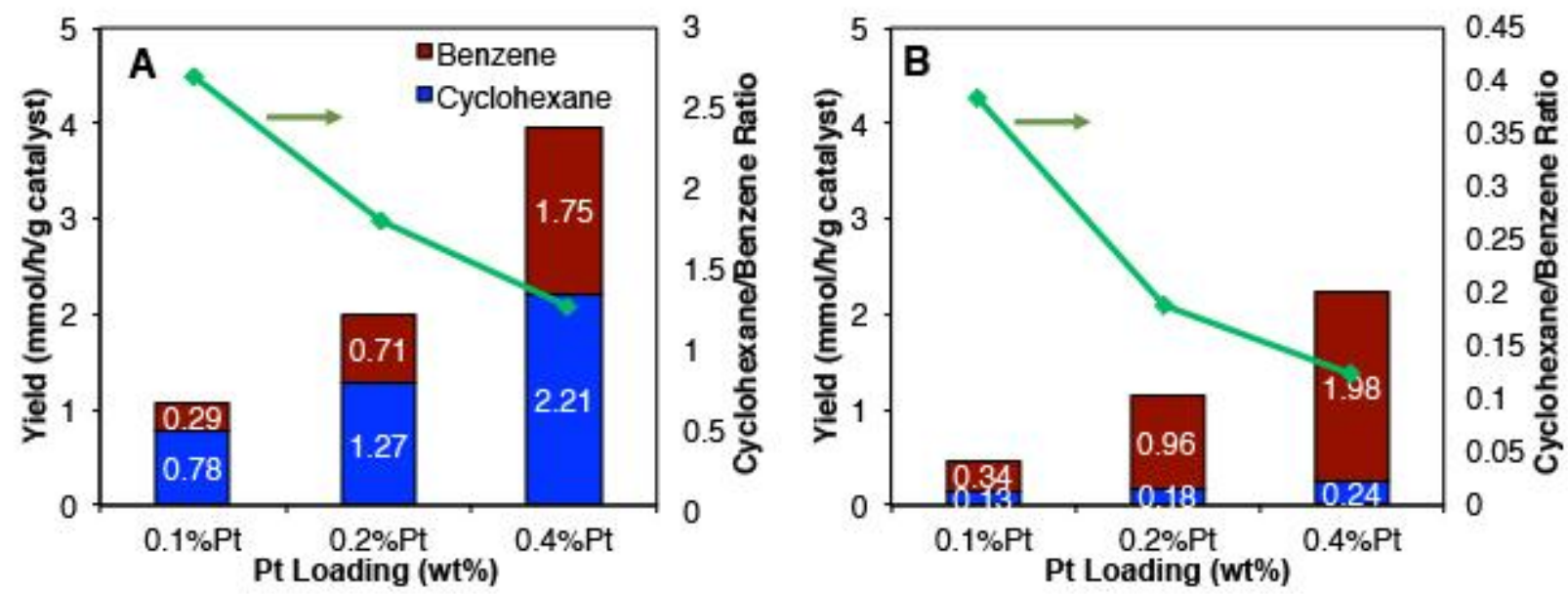

Figure 4. Effect of Pt loading (ca. 0.1, 0.2 and 0.4 wt\%) supported on (A) BEA-10 and (B) BEA-0.5 zeolites. Red and blue bars are benzene and cyclohexane, respectively. Green lines are the benzene/cyclohexane ratio calculated from their product yields. 

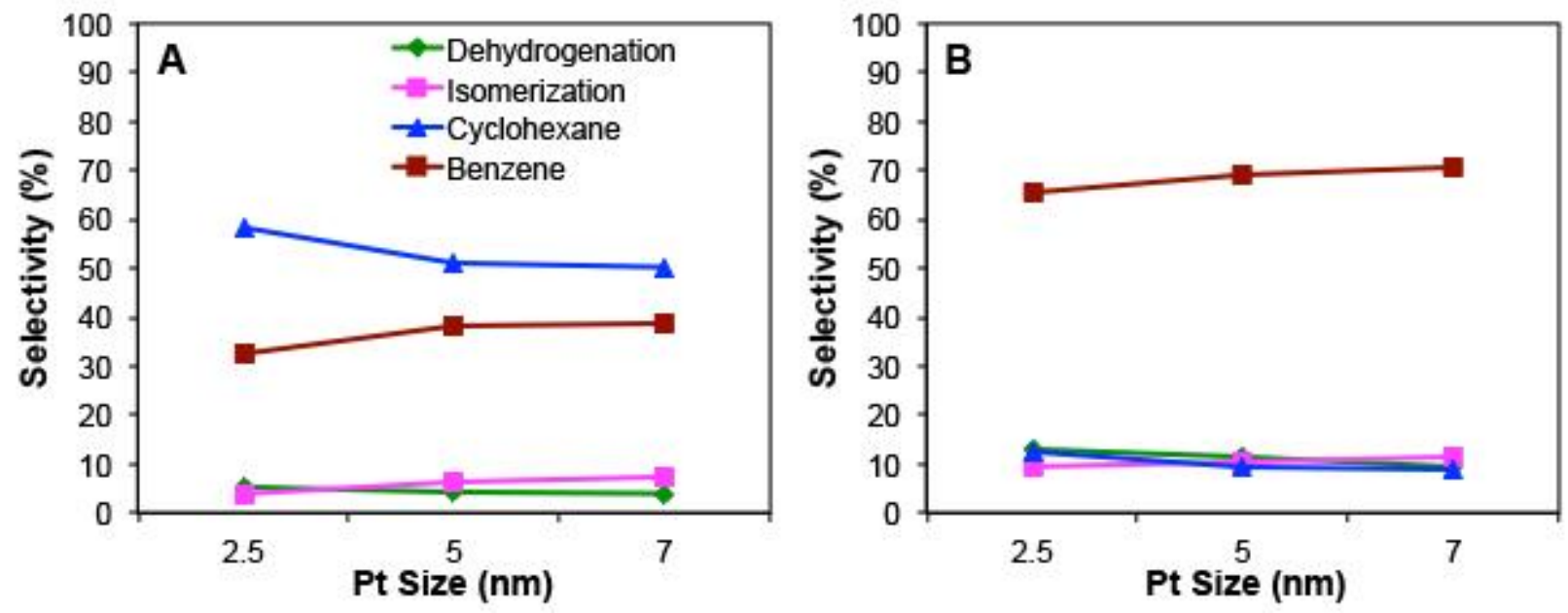

Figure 5. Effect of Pt size (ca. 2.5, 5, $7 \mathrm{~nm}$ ) supported on (A) BEA-10 and (B) BEA-0.5 zeolites.
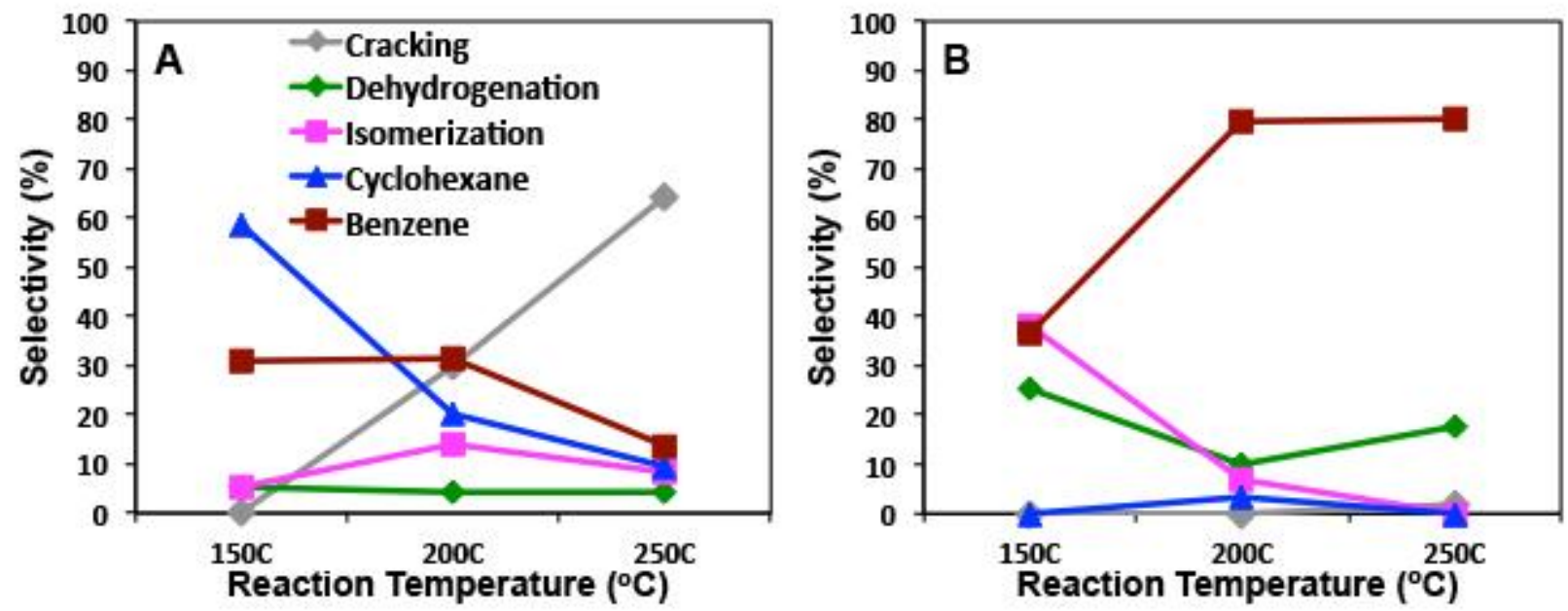

Figure 6. Effect of reaction temperature $\left(150,200,250^{\circ} \mathrm{C}\right)$ on the product selectivity over (A) Pt/BEA-10 and (B) Pt/Al-SiO -10 catalysts. $2.5 \mathrm{~nm}$ Pt NPs with ca. $0.2 \mathrm{wt} \%$ loading was fixed to both catalyst systems. 

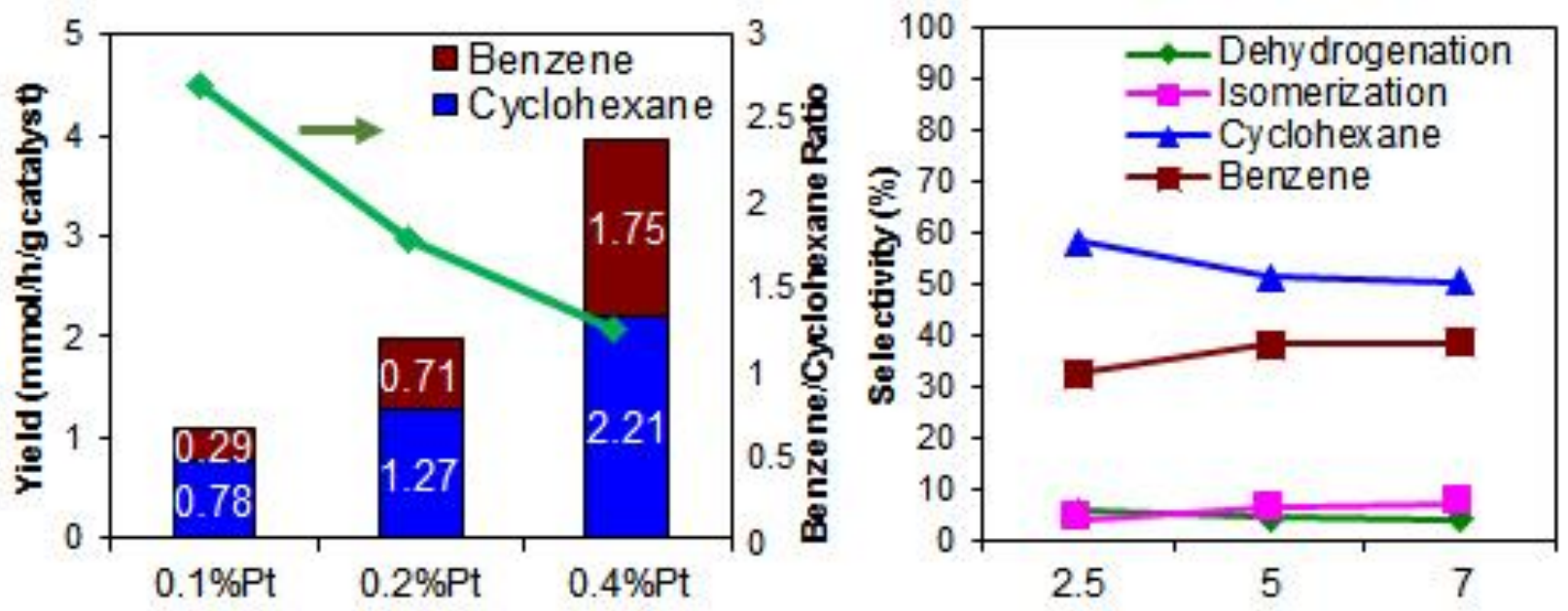